ERJ

Englneering Research Journal

Faculty of Engineering

Minoufiya University

\title{
A PHYSICAL MODEL TO INVESTIGATE A NEW ALIGNMENT OF COASTAL GROINS
}

\author{
Al Sayed I. Diwedar ${ }^{1}$, Sonia El-Serafy ${ }^{2}$, Abdel Azim M. Ali ${ }^{3}$, Yasser El Saee ${ }^{4}$ \\ I, Hydrauliçs Research Institute (HRI), Egypt \\ ${ }^{2,4}$ Ain Shams University, Egypt
}

\begin{abstract}
Undistorted fixed bed physical model was used to examine a new groins alignment, which is not connected to the shoreline, in order to reduce the downdrift erosion and to minimize the trapped sediment at the updrift. The model was constructed in the wave basin of the Hydraulics Research Institute (HIRI), Delta Barrage, where both wave height and current velocity, in two directions, before and after the groins' construction were measured.

The physical model succeeded in simulating the coastal groins and relating phenomena which helped to understand the complex interaction between waves, current, sediment, and groins. It was concluded that the proposed alignment is successfully reduced the erosion in the downdrift and allowed movement of longshore sediment transport and protects the located area between the groins.

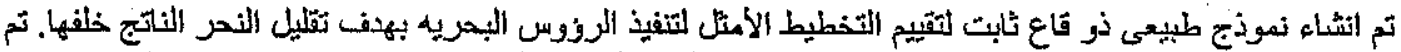

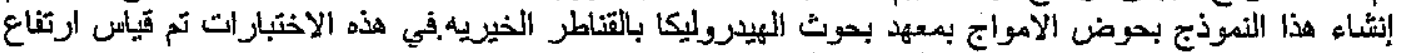

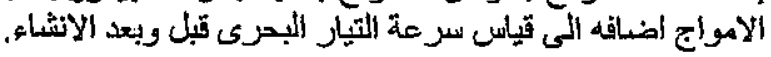

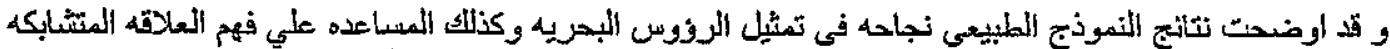

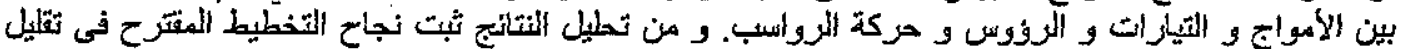

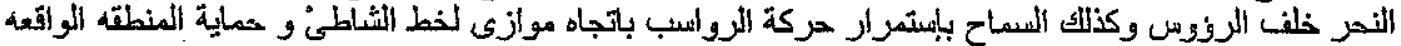

بين الروزوس.
\end{abstract}

Keywords: Coastal groins, groins alignment, functional design, alongshore sediment transport.

\section{INTRODUCTYON}

The coastal zone, worldwide, is counted to be a very important area which suffers from erosion and accretion problems that might be overcome by implementing the classical groins. For that reason the coastal groins could be used to face the erosion problems that result from the longshore sediment transport. Downdrift erosion is a result of the groin obstruction to the sediment movement alongshore which puts a limitation to the groin use.

The groin structure is the oldest used shore connected stabilizing structure. It is usually set perpendicular to the shoreline. It extends from a point above the high water level to a point higher than the low water level. Groins were used at the early $14^{\text {th }}$ century in northern Europe and were used along the Dutch coast in the $16^{\text {th }}$ century. On the other hand, the groins built in America are recently used. The groin is defined according to the US ARMY (1994), as an alongshore protection structure that can be designed to trap the alongshore drift for building a protective beach, retarding erosion of an existing beach, or preventing long shore drift from reaching some downdrift point, as harbor or inlet.
The groins were first built of wood and poles as the case of Blankenberge, Dutch 1502. In Belgium masonry groins with twinge bundle core, stone blocks fixed. with wooden hooks and rods (to preserve the masonry) were used after that. Modern groins (rubble mound, concrete, asphalt, and etc) were placed in the $20^{\text {th }}$ century. In Belgium as in The Netherlands, it has been said that, groin has a positive impact but De Moor and Blomme (1988) changed this idea.

More information about groins is still needed. The groin functional design lacks design formulas. It is the most abuse and unacceptably designed of all coastal structures US ARMY (2003). Kamphuis (2005) argues that, knowledge about groins is still important. It was stated also, that due to the complex interaction between water, sediment and groins, the functional design of groins is carried out on the rule of thumb. On the other hand, when the groins are improperly aligned, erosion at the dowñdrift will take place. This puts a limitation to the groin use. Efforts are done to reach an acceptable formula that connects the design parameters to each other in order to face this difficulty.

This paper presents a physical model constructed to examine a new groin alignment with the objective of 
understanding the hydrodynamics and sedimentary processes related to the groins and examining their ability in reducing the downdrift erosion due to their presence. Physical and mathematical models are very useful tools to understand the hydrodynamics and sedimentary processes related to the groins. The physical model is more efficient to give a very clear insight to the interaction between waves, current, sediment, and structure. Therefore, a physical model was implemented in this study.

\section{LITERATURE REVIEW}

The literature on groins may appear to assign validity to certain concepts and conclusions by weight of repetition but not by independent confirmation, Kraus, Hanson, and Blomegren (1994). Kraus and Bocamaza (2000) stated that there is a need to determine how much sand can be allowed to pass, while still maintaining a minimum width of beach at the groin for some level of shore protection.

Kamphuis (2005) concluded that groins can not protect against cross shore erosion. It can only change the alongshore transport rate thus protecting alongshore erosion. However; the downdrift erosion will occur at the downdrift. Also, it was stated that models are needed, especially the numerical models, to predict the sediment change due to groin construction. There is a need to correct groin design to fit to the near and far sediment field.

Cornett (2003) reviewed two physical model studies on coastal groins in the Canadian Hydraulics Center (2002). It was argued that the mobile-bed physical model is a very useful tool for engineers in the coastal engineering studies to optimize the problem solutions providing the interaction between waves, sediment, and structures. It could help in choosing between different alternatives. Hanson and Kraus (2000) did not agree with the advantage of the Thead groin compared to the detached breakwater. It was argued that the downdrift erosion is larger in case of the T-head groin.

It can be concluded from literature, that there is two problems related to the groin usage which are as follow:

- The resulting downdrift erosion extending to a non-eroding point

- The absence of a mathernatical equation for the groins functional design.

\section{PHYSICAL MODEL}

In crier to investigate the proposed groin alignment and compare it to the traditional one, undistorted fixed bed physical model with scale 1:40 was constructed in the coastal experimental hall of the Hydraulics Research Institute (HRI). This basin is $31 \mathrm{~m}$ wide $34 \mathrm{~m}$ long, Figure (1) and equipped with a
$25 \mathrm{~m}$ long wave generator which is able to produce a wave height up to $15 \mathrm{~cm}$. The wave generator is able to produce regular and irregilar waves. In this study a JONSWAP spectrum was used.

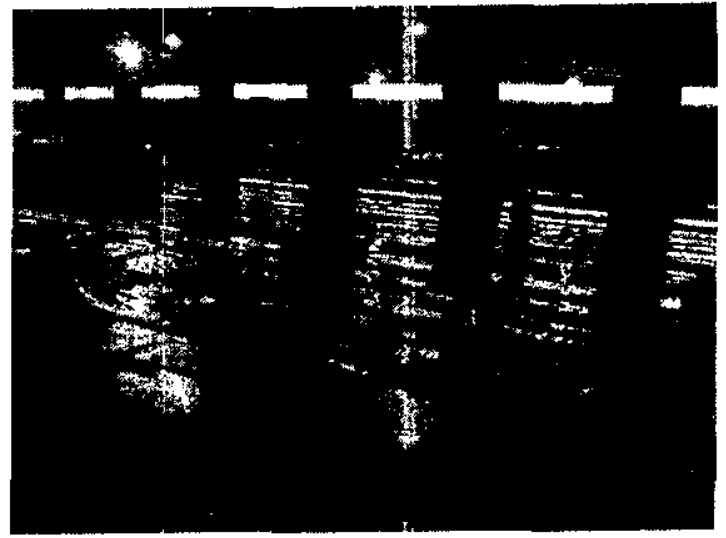

Figure 1 HRI wave basin

\subsection{Model Construction}

The model was constructed $n$ one month time; the test program was executed in three months. Cemented mortar was used to simulate the sea bed. Bed bathometry was formulated using leveling instruments, Figure (2).

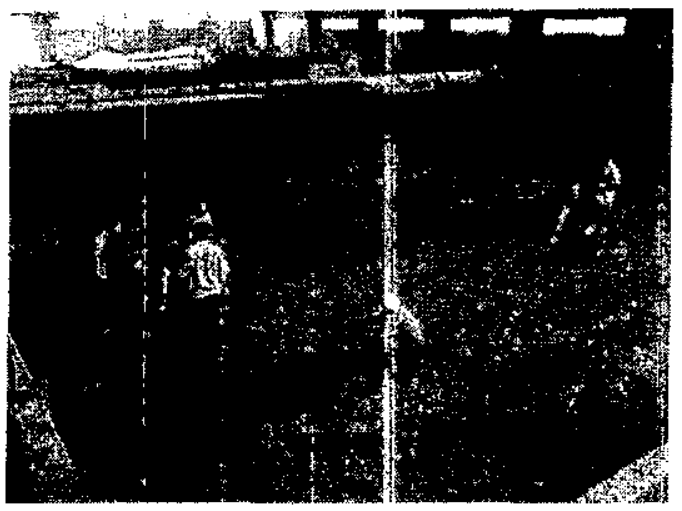

Figure 2 Bed leveling

One cross shore profile was used in the whole study area as shown in Figure (3). The bed slope is chosen to be 1:30. This represents the mean slope of the Egyptian beaches.

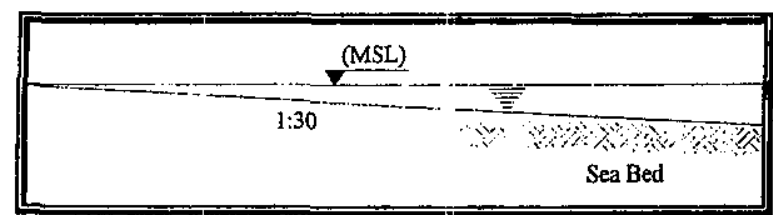

Figure 3 Cross shore profile

The tested groins cross secticns were manufactured from a wooden form then placed at its location and filled with stones, as shown in Figures $(4,5)$. 


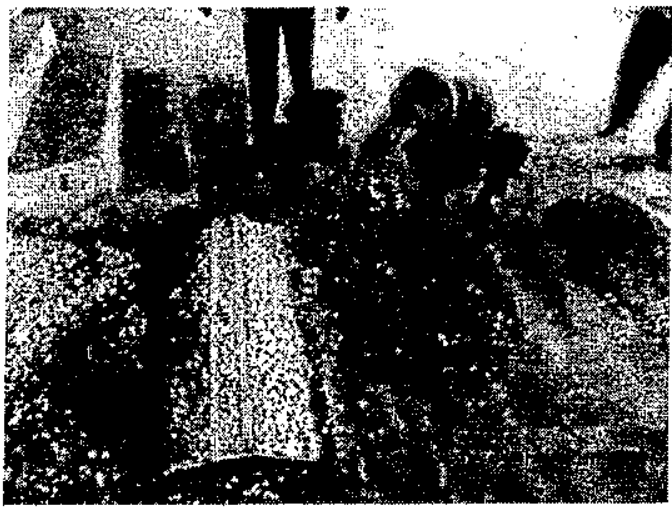

Figure 4 Groins cross section

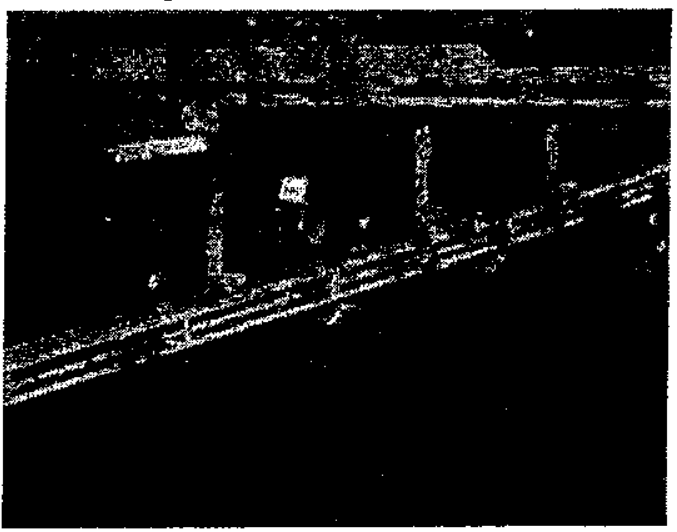

Figure 5 Groins in the wave basin

Figure (6) illustrate the designed cross section for the short groin $(\mathrm{L}=50 \mathrm{~m})$.

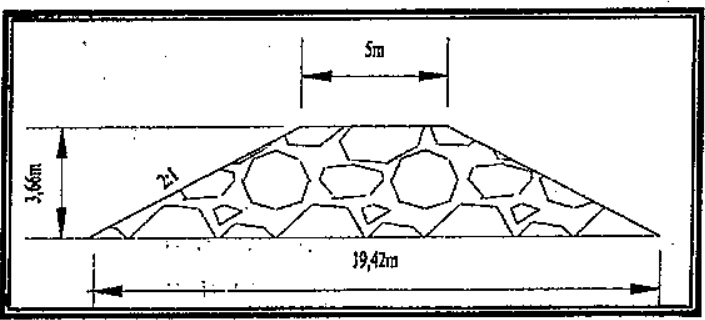

Figure 6 Groin cross section for $\mathrm{L}=50 \mathrm{~m}$

The simulated coastal area was constructed and has an oblique angle with the wave direction, Figure (7). This was done in order to produce longshore currents which are important to test the function of the proposed groins aligument.

\subsection{Measuring Devices}

Several measuring devices were used during the experiments, which can be elaborated as follows:

- Point gauges to adjust the water level.

- Wave height meters (WHM), which are designed for the dynamic fluid level measurements.

- An electro-magnetic current meter (VLM) and time series velocity to measure the average velocity components in $\mathrm{x}$ - and $\mathrm{y}$-directions.

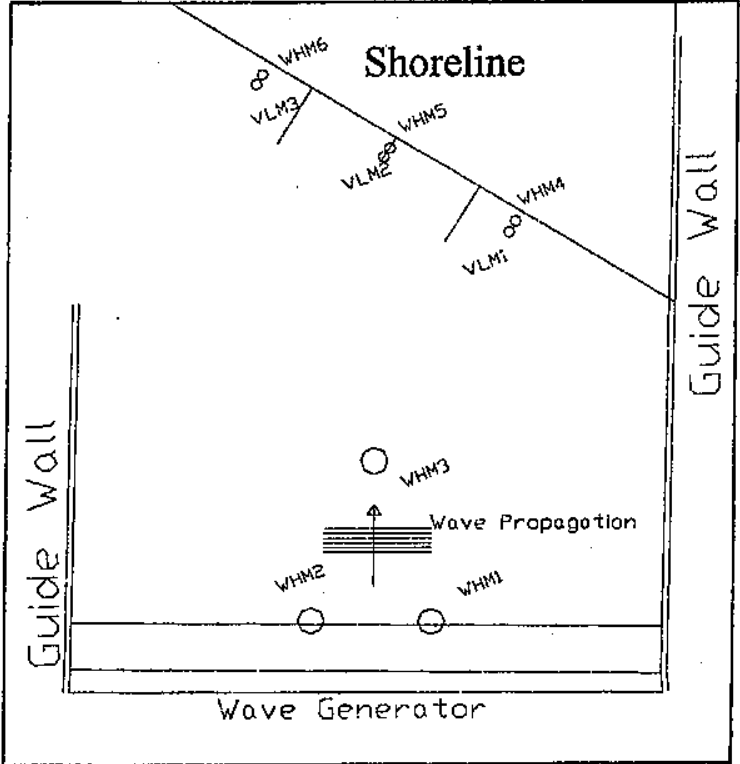

Figure 7 Approaching wave and instruments location

\subsection{Undertaken Measurements}

Several measurements were undertaken during the experiments, for example:

- Wave height was measured in the deep water to ensure the generated wave heights to be equal to the designed wave. The wave height is measured at three locations around the groin system, $1.5 \mathrm{~m}$ updrift the first groin, between the groins, and at $1.5 \mathrm{~m}$ downdrift the last groin.

- The longshore current velocity was measured as well at the previous location

- Visual observation.

Figure (8) shows the arrangement of the used measuring devices and the devices location inside the basin.

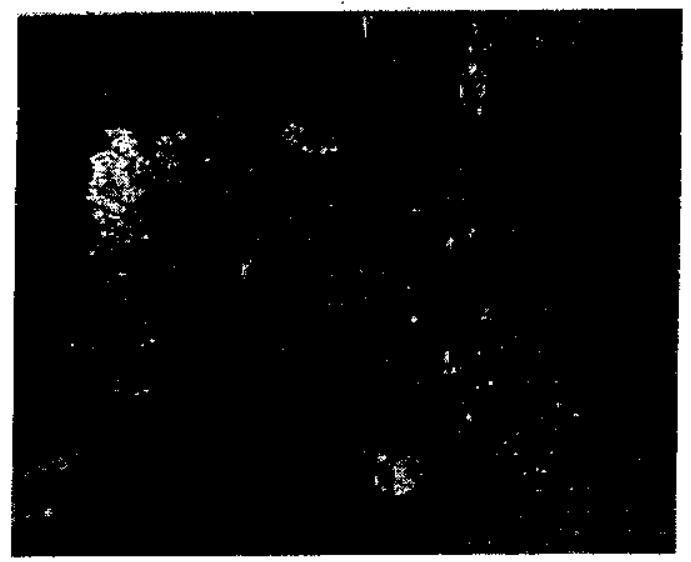

Figure 8 Instrument arrangement

The software package AUKE/pc is used in the measurements. This software can be used both for the data acquisition of measuring signals and the 
generation of wave control signals. The control signals are applied for the wave generator.

\section{TESTING PROGRAM}

Accordingly a test program (243 tests) was designed to examine different groin parameters as in Table (1).

Table 1 Test conditions for one wave angle

\begin{tabular}{|c|c|c|c|c|c|c|c|}
\hline$H(m)$ & $\begin{array}{c}L \\
(m)\end{array}$ & \multicolumn{3}{|c|}{$X(\mathrm{~m})$} & \multicolumn{3}{c|}{$Y(\mathrm{~m})$} \\
\hline 1.5 & 50 & 50 & 100 & 150 & 0 & 10 & 20 \\
\hline 3.5 & 80 & 80 & 160 & 240 & 0 & 16 & 32 \\
\hline 5.5 & 110 & 110 & 220 & 330 & 0 & 22 & 44 \\
\hline
\end{tabular}

Three groin parameters were tested which are as follows

-* Groin length (L),

- Groins spacing (X),

- Distance from shoreline (Y).

$\checkmark$ In addition, two wave climate parameters were chosen to be examined which are

- Wave height $(\mathrm{H})$.

- Wave angle $(\theta)$.

The test program included three wave angles of $(\Theta=15,30$, and $45 \mathrm{deg})$. For each angle, three wave heights of $(\mathrm{H}=1.5,3.5$, and $5.5 \mathrm{~m})$ were tested.

For each wave height, three offshore distances $(\mathrm{Y})$ as a percentage of groin length were investigated. For every distance from the shoreline, three groin Jengths $(\mathrm{Lg}=50,80$, and $110 \mathrm{~m})$ were tested where for each length three groin spacing of $(X=L, 2 L$, and $3 \mathrm{~L})$ were examined, Figure (9), and Figure (10).

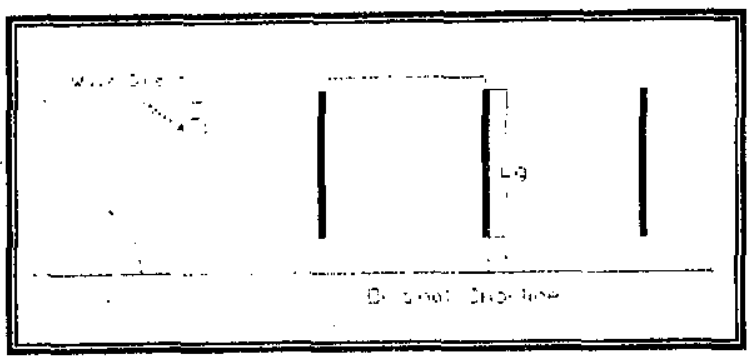

Figure 9 Test arrangement

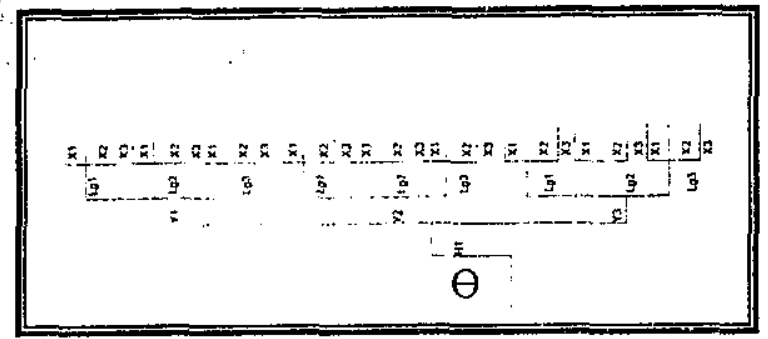

Figure 10 Testing program

\section{Procedure}

The given steps were followed to undergo every run of the designed test program.

- Filling the wave basin with water

- Adjusting the water level

-. Adjusting the measuring devices

- Affixing the instruments to its location

- Preparing steering file for wave generator using the AUKE/pc software

- Running the test

- measuring wave heights and velocities through the controlling unit (data logger connected to the computer system)

-. Processing the measured data using AUKE/pc software

- Analyzing the results for each test

\section{RESULTS}

Measured wave height and current velocity were analyzed according to the wave angle. A sample of the measurements is given on Figures (from 11 to 16). The tests show the impact of the different groin parameters on the wave and current and velocity pattern with different wave angle.

The measured wave height was found to improve when the groins spacing vas reduced, while the current velocities improve when longer groins installed at large groin spacing.

From the analyses, the best vector patterns was found to occur when the approaching wave angle was $30^{\circ}$, and a groin spacing was $3 \mathrm{~L}$. This occurred for a groin length of $110 \mathrm{~m}$, groin spacing of $330 \mathrm{~m}$, and a distance from shoreline of $44 \mathrm{~m}$, Figure (17). The analyses showed that in this case the current velocity had almost the same direction and had almost equal values. This was observed for all the tested lengths. This was also observed at the downdrift where the vectors are directed towards the offshore; consequently, less erosion is expected.

\section{CONCLUSIONS AND RECOMMENDATIONS}

From the above, the following conclusions are drawn:

- The study helped to understand the complex phenomena related to the groins construction and the impact of the differen: designing parameters.

- The physical model succeeded to simulate the coastal groin system and ts related phenomena

- The experiments showed that the new alignment proved to be applicable for the Egyptian coast as the Egyptian conditions were used during these runs.

From the above conclusions, it can be recommended to:

- Apply the proposed alignnent to a pilot area. 
- Introduce the proposed alignment to the Egyptian practice.

- Undergo further studies to validate the proposed alignment to be applicable at different areas.

\section{REFERENCES}

[1] Cornett, A.M., 2003.

"Recent Experiences with Physical Modeling of Beaches. Canadian coastal conference.

[2] De Moor,G.and Blomme,E., 1988 Belgium. In Artificial Structures and Shorelines. Ed. H.J. walker, 115-126, Kluwer, Dordrecht, The Netherlands.

[3] Hanson, H., and Kraus, N.C., 2000.

Representation of Tombolos and Sediment Transport by Tidal Currents in GENESIS Model. Processing $13^{\text {th }}$ annual national conference on beah preservation technology, Florida shore and beach preservation association, Tallahassee, Fl, 64-80.

[4] Kamphuis, J.W., 2005.

Groins and Coastal Zone Management. Canadian coastal conference 2005.

[5] Kraus, N. C., and Bocamazo, L. M. 2000.

"State of Understanding of Groin Functioning and Recent Promising Innovations," Proceedings, 3rd Annual Conference, Northeast Shore and Beach Preservation Assoc.;

[6] Kraus, N. C., Hanson H., and Blomgren, S. H. 1994.

"Modern Functional Design of Groin System," Proceedings, 24th International Conference on Coastal Engineering, ASCE, NY, pp 1327-1342

[7] US Army Corps of Engineers, 2003. Coastal Engineering Manual, Department of the army, Washington,DC 20314

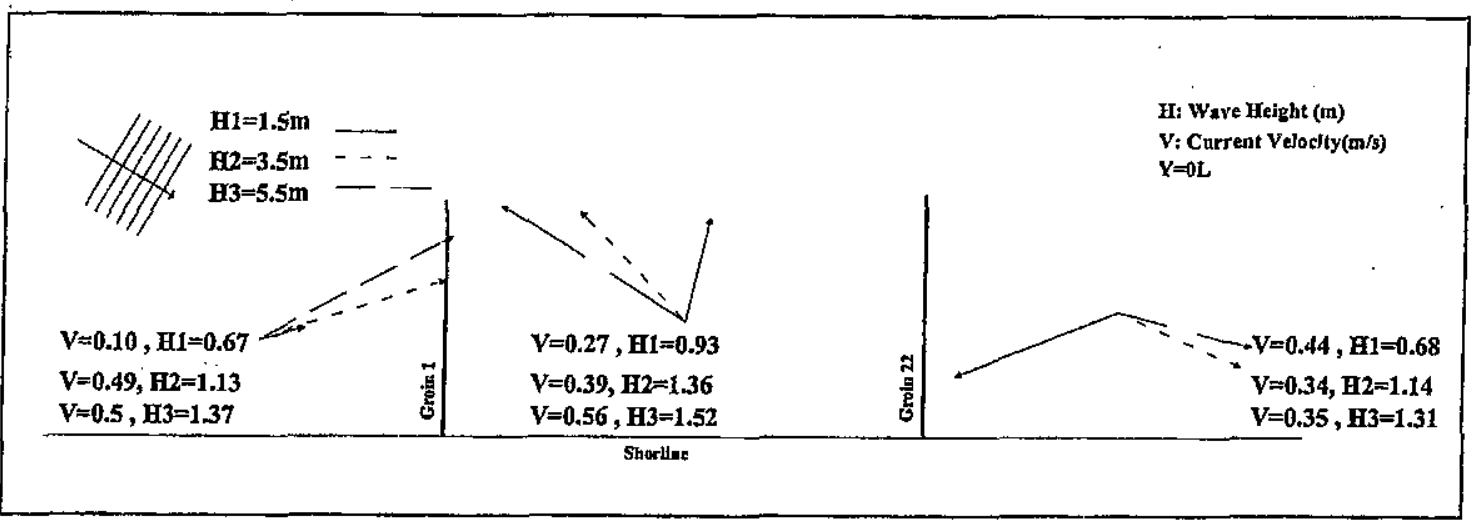

Figure 11 Current vector and wave heights for wave angle $15^{\circ}, L=50 \mathrm{~m}, X=100 \mathrm{~m}$, and $Y=0 \mathrm{~m}$

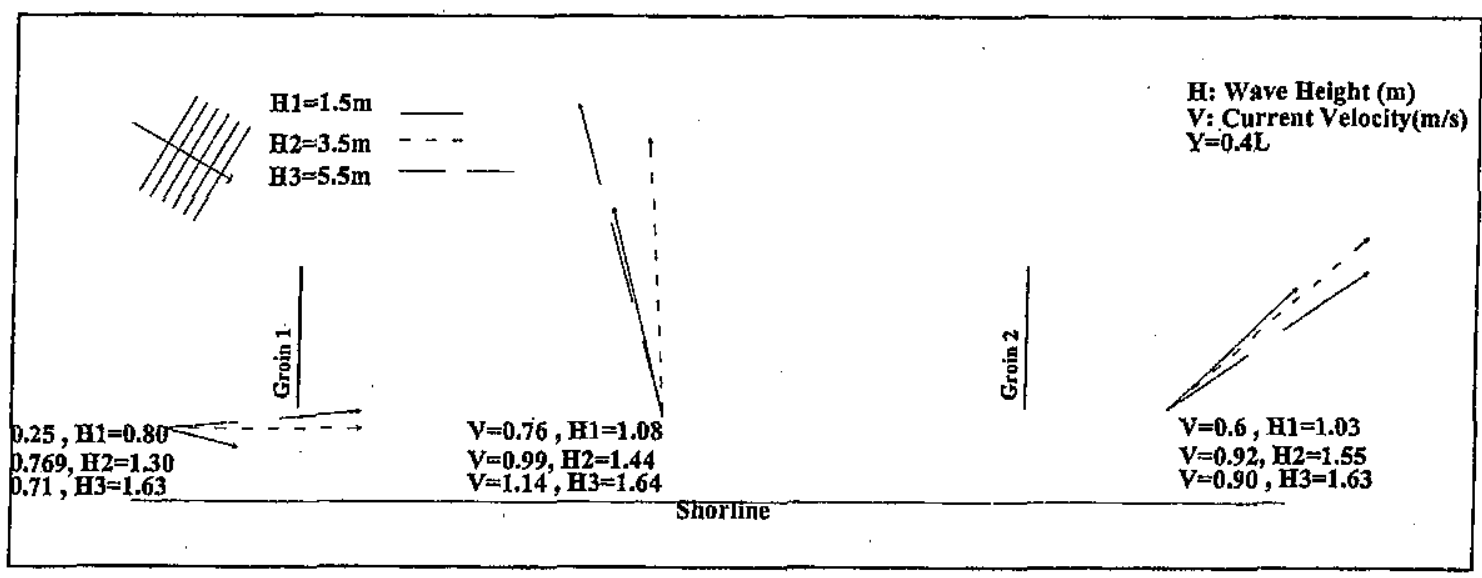

Figure 12 Current vector and wave heights for wave angle $15^{\circ}, L=110 \mathrm{~m}, X=330 \mathrm{~m}$, and $Y=44 \mathrm{~m}$ 


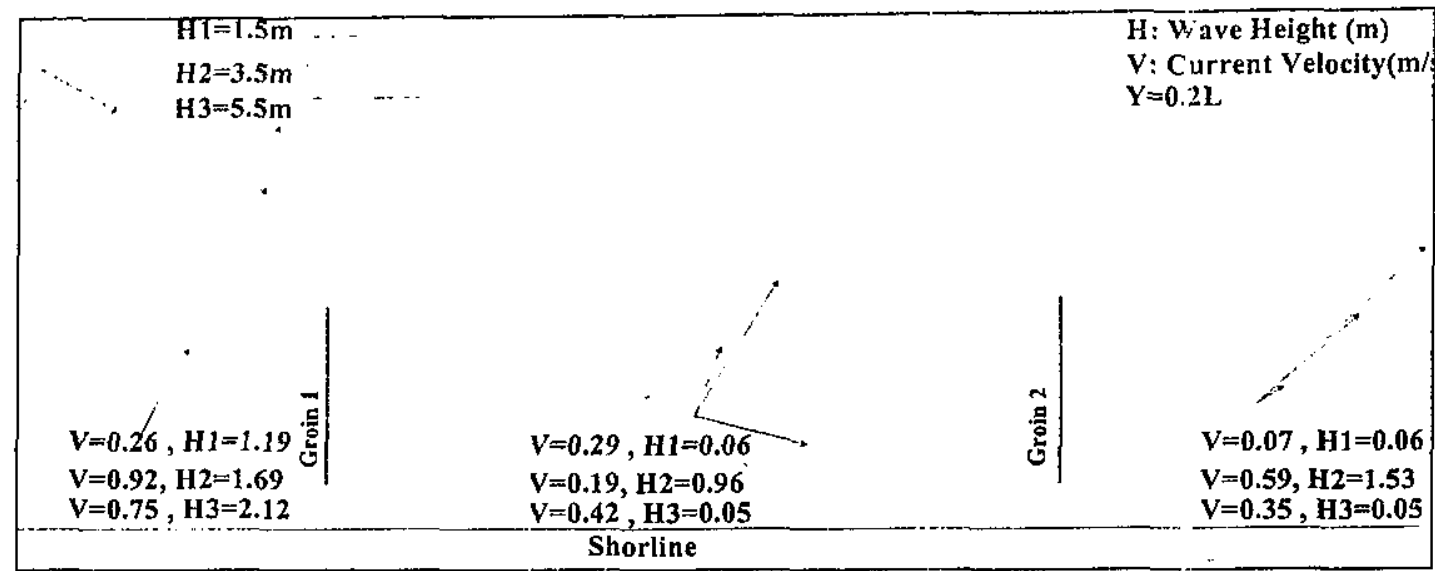

Figure 13 Current vector and wave heights for wave angle $30^{\circ}, \mathrm{L}=80 \mathrm{~m}, X=160 \mathrm{~m}$, and $\mathrm{Y}=16 \mathrm{~m}$

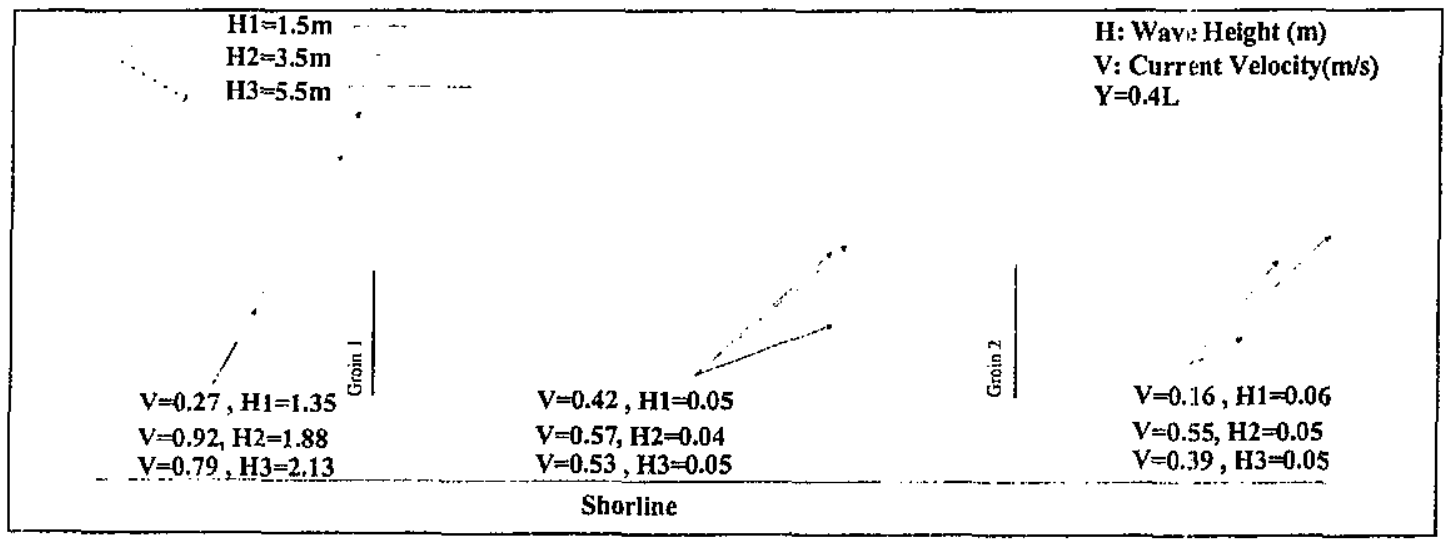

Figure 14 Current vector and wave heights for wave angle $30^{\circ}, L=80 \mathrm{~m}, X=240 \mathrm{~m}$, and $Y=32 \mathrm{~m}$

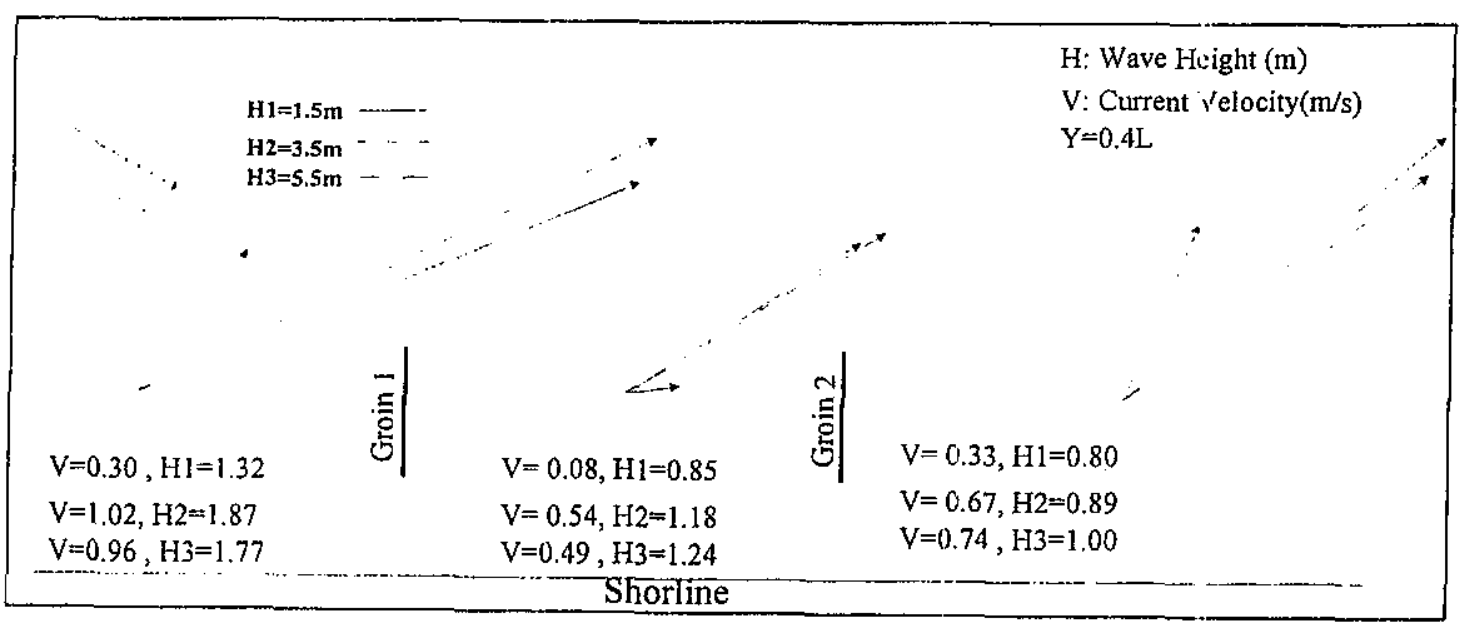

Figure 15 Current vector and wave heights for wave angle $45^{\circ}, \mathrm{L}=50 \mathrm{~m}, \mathrm{X}=150 \mathrm{~m}$, and $\mathrm{Y}=20 \mathrm{~m}$ 


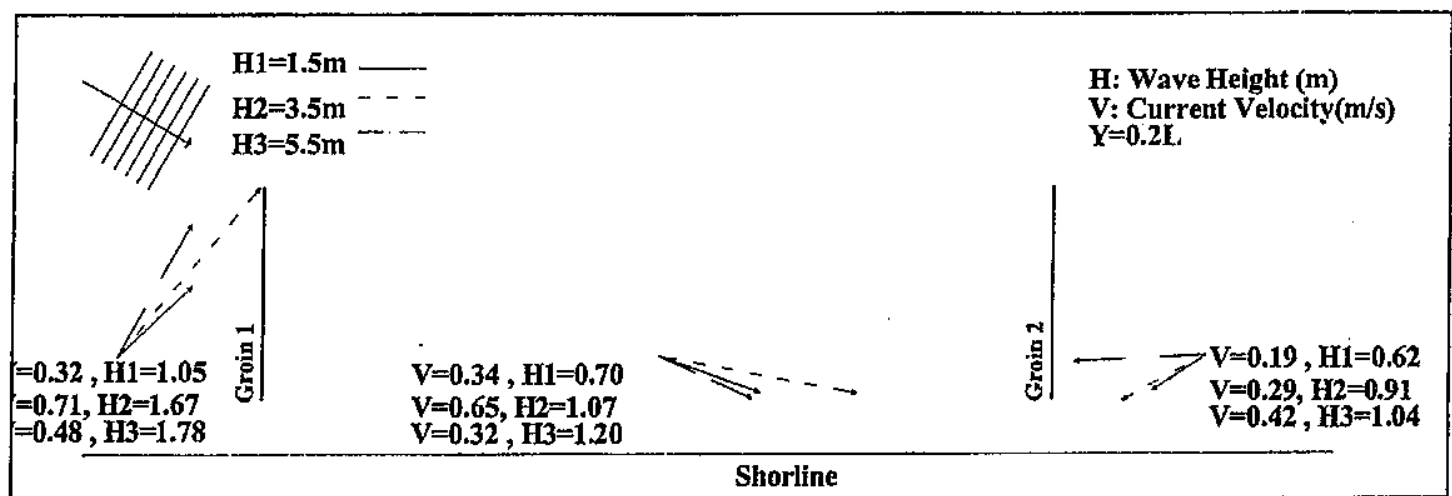

Figure 16 Current vector and wave heights for wave angle $45^{\circ}, L=110 \mathrm{~m}, X=330 \mathrm{~m}$, and $Y=22 \mathrm{~m}$

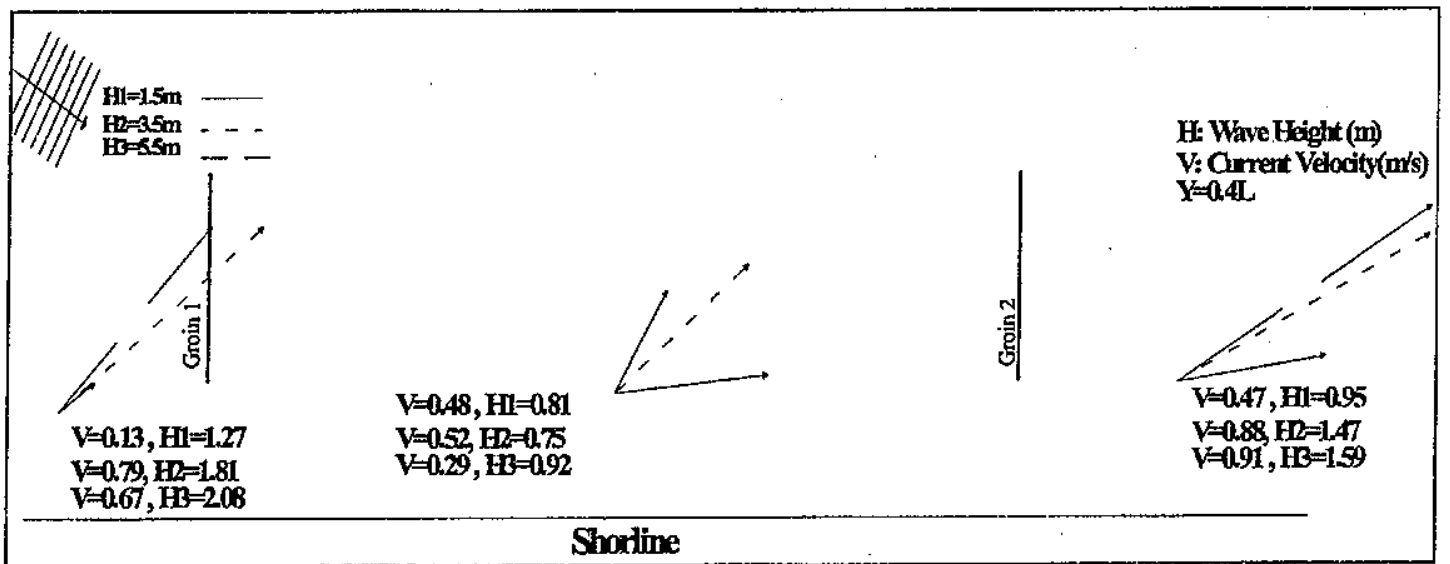

Figure 17 Best tested case 